\title{
THE ROLE OF DIGITIZATION IN POST-DISASTER RECONSTRUCTION
}

\author{
M. Rotilio ${ }^{1 *}$, B. Tudini ${ }^{1}$ \\ ${ }^{1}$ Dept of Civil, Construction-Architectural and Environmental Engineering, University of L'Aquila, Italy - \\ (marianna.rotilio@univaq.it, benedetta.tudini@student.univaq.it)
}

Commission IV

KEY WORDS: Digitization, BIM, Construction, Stakeholders, Post-disaster reconstruction

\begin{abstract}
:
Nowadays, it is well known that digitization has tenaciously become part of the construction industry. The document is aimed at being an analysis of the state of the art, focusing on the digitization application in post-disaster reconstruction. The new technologies have influenced all the actors involved to adapt to a new designing way, but this methodology brings with itself advantages and disadvantages. This paper will try to identify, clarify and review them. In fact, it will try to explain to what extent the logic related to the design and construction of the post-disaster area may be guided by a single common thread, that consists in the Building Information Modelling (BIM) methodology use. Through this methodology it is possible to reduce time and improve costs, thanks to the possibility to optimize the design and construction processes and to carry out virtual inspections and analysis based on the information from the construction phases. In addition, the various BIM tools, that allow interoperability, guarantee a semi-automatic review of the project's compliance with regulations and interference between the different design levels (structural, architectural, plant engineering and energy). In this way, there is the chance to improve the accuracy and reliability of the validation process. The entire process is also based on a multidisciplinary approach involving all branches of engineering.
\end{abstract}

\section{INTRODUCTION}

In the current historical period, the digitization process is in first place among the activities and objectives to be pursued. It involves every actor of all levels (government, small and medium-sized enterprises, large companies) in order to create value, to optimize resources and to make work organization more efficient.

According to what is reported by the synthetic formalism of a dictionary, the term digitization means: "translation between two different systems in order to transmit and record information. In this process, the start is an analog signal, that is composed of a quantity that can change over time and take on an infinite number of different values, such as a wave. It faithfully follows the changes in the phenomenon it represents. Instead, the analog signal is transformed into a sequence of distinct, digital values, each expressed by a number."(Nosegno, 2005). In the Italian context, the importance of this subject is well-known. In fact, the Economic Development Ministry has placed an industrial plan called "Industry 4.0" at the centre of its agenda. This plan is aimed at modernizing the industrial sector, through the integration of innovative technologies and the digitization of the manufacturing world.

The construction sector is involved with the same intensity as the other sectors and the potential advantages have been highlighted: they could completely revolutionize the concept and approach to this field. In particular, applying digital transformation to the construction sector, the reference is made to the design and management of processes through the sharing of information in electronic, organized and processable form. The most effective operational model to pursue digital transformation in this sector is the Building Information Modelling (BIM).
Therefore, the aim of this contribution is to provide an overview of this process progress in the current context, starting from the evolution of digitization in the construction world, up to the management of post-disaster scenarios.

\section{THE DIGITIZATION OF THE CONSTRUCTION WORLD}

\subsection{Evolution of digitized systems in the construction market}

The digitization is a process that dates from the 1970s and, unlike what one might think, it is not a momentary phenomenon as a result of a current trend, but it is a real paradigm shift (Ferrara and Feligioni, 2016). In particular, Building Information Modelling (BIM) is currently considered as the most innovative methodology in the construction sector (Vilutiene et al., 2019). A 1992 publication (Van Nederveen and Tolman, 1992) contributed to its large-scale diffusion, as well as the 2003 publication of the AutoDesk White paper (Miramonti, 2014).

Bernstein and Laiserin were two of the main protagonists of the diffusion and standardization of the term (Miramonti, 2014), in relation to which the term BIM was intended, as a standard definition, for the digital realization of the building process (Lucarelli et al., 2018). The Italian National Unification Institution, known as UNI, from the beginning tried to define technical specifications through the enactment UNI 11337:2009, later replaced by UNI 11337-1:2017, which still represents the main guideline on the subject of digital management of BIM processes. This legislation is divided into ten parts, seven of which have already been published. They

\footnotetext{
* Corresponding author
} 
deal with the general aspects of the information processes digital management in the construction sector, such as:

1. The information vehicle structure;

2. The process information structure;

3. The product information structure.

The regulatory structure consists of 10 parts, four of which have not yet been issued (Table. 1).

Further measures, that are particularly important, were taken in recent years, after the the 2014 Community Directives 23, 24 and 25. Among them, the 2014/24/EU invites Member States to encourage, specify or impose the BIM use for all publicly funded projects and works in the EU, starting from 2016. In Italy, the implementation of these community guidelines took place through Legislative Decree 50/2016 which introduces, in article 23 paragraph 13, the gradual adoption. The turning point, however, took place with the Ministerial Decree $560 / 2017$, which introduces the requirement of BIM in the context of public procurement. Starting from 2019, the use of BIM has been made compulsory for complex works related to works with a tender amount equal to or greater than 100 million. This threshold will be reduced annually until 2025: in that year is expected the BIM adoption for all public works.

Despite the aforementioned premises, which show that BIM has been discussed at length, in actual fact the BIM concept, not just understood as a simple 3D model, has only been clarified in recent years and in the most advanced countries. In this regard, the US National BIM Standard (NIBIMS) defines that the "Building Information Modelling is the digital representation of the physical and functional characteristics of a structure, which creates a shared knowledge resource in order to obtain information on the building, and a reliable basis for all decisions during its life cycle, from initial design to demolition". The limiting use as a simple tool of mere threedimensional representation is however giving space to its actual use (Miramonti, 2014).

In Italy, the so-called BIM Decree just mentioned was the driving force for its diffusion. In fact, according to the third OICE Report on BIM (OICE 2019), the tenders monitoring carried out by the Institution starting from July 2015, initially saw a timid growth, which became consistent especially after the approval of the Ministerial Decree 560/2017 (Fig.1). In particular, in the context of the procedures for the award of engineering and architecture services, the Report highlights a further leap of $58.3 \%$ in 2019 , after the growth of $263.9 \%$ in 2018.

\begin{tabular}{|c|c|c|}
\hline \multicolumn{3}{|c|}{ STANDARD UNI 11337.2017 } \\
\hline Part & Description & Publication \\
\hline 1 & Models, drawings and object & Published in 2017 \\
2 & Denomination and classification & - \\
3 & (Information cards) - LOI and & From 2009 \\
& LOG & \\
4 & LOD and objects & Published in 2017 \\
5 & Management of models and & Published in 2017 \\
& documents & Published in 2017 \\
6 & Informative specification & \\
& example & Published in 2018 \\
7 & Figures definition & - \\
9 & PM / BIM - M & - \\
10 & Building book & - \\
\hline
\end{tabular}

Table 1. The main contents of the UNI 11337-1:2017 standard

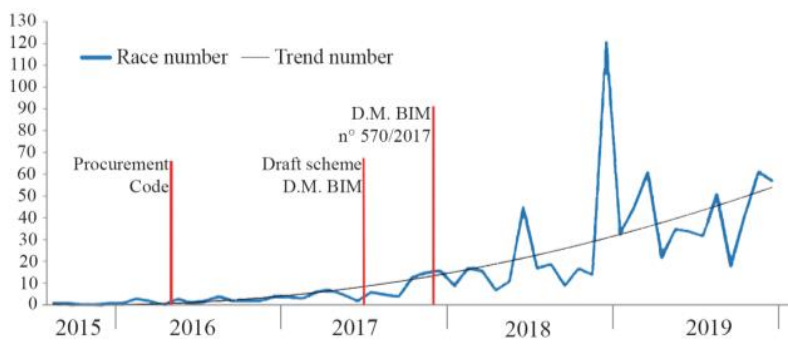

Figure 1. BIM tenders trend monitoring (OICE 2019)

In terms of value, the BIM tenders raised 296.3 million euros against the 1,502 million of the entire engineering and architecture services market and represent $19.7 \%$ of the tenders issued.

This growth highlights the prospect of going further beyond the well-known borders of digital and technological innovation.

But despite these encouraging data, it is clear that this is still a transition phase. In fact, as it normally happens for any novelty, it is possible to identify dichotomies in relation to the concept of digitization, especially when the aim is to introduce this methodological approach in a sector that is not very open to process innovations, such as the construction world. Therefore, a reflection on this issue is reported in the following paragraph.

\subsection{Dichotomies about the world of digitization}

The growing development of the building industry has led to the launch of multiple challenges from the world of traditional construction. These difficulties involve several aspects, including (Qin et al., 2020; Li et al. 2014):

1. Complex construction technologies;

2. Large investments;

3. Difficult planning;

4. Involvement of different stakeholders;

5. Large amount of information to organize.

In order to manage critical issues, a process digital revolution was necessary, a sort of paradigm shift, from the world of construction in general to the management and maintenance of buildings in the particular. This was possible by promoting and implementing the BIM use from the origin of the work conception to its maintenance, through the concept of Facility Management (FM). This tool is based on the perfect knowledge of the building's executive and construction methods (as-built), the transformations it has undergone over time and, clearly, its real condition (as-is) (Osello and Ugliotti, 2017).

The purpose of this methodology is the integration of planning with computerization, governing processes and promoting smart management of costs, quality and time. This solution is aimed at reducing errors, decreasing the in-process variations number, improving the quality of the building design and construction, enhancing efficiency of communication and the collaboration between the many protagonists of the building process, increasing productivity, ensuring greater workers safety, mitigating risks. These are the objectives, but also the advantages, that could be achievable with the digitization of the built heritage. On the other hand, there are still many problems to overcome, such as the poor interoperability between systems, the difficult cooperation, the lack of sector professionals, the resistance to change, the delay in adopting common legislation and the insufficient management of procedures and methodologies (Ciribini, 2018). As a consequence, the 
information model finds little application from the geometricdimensional point of view and the alpha-numeric component is systematically excluded (Fig. 2).

The design goal still remains analog, because in the common mindset the graphic is prepared with the aim of using it for contractual agreements. Even admitting that information modelling is used to draft documents, the clash detection (Fig. 3 ) involves a series of conflicts between the architectural, structural, plant and energy fields, due to the poor interoperability between the different areas. Moreover, the role of $4 \mathrm{D}$ and 5D BIM is almost never perceived both in relation to the space and construction sequences and in relation to management and performance indicators (Ciribini, 2019a). In fact, the digitization role in the executive phase is not considered for its right value, forgetting, for instance, how its use could be efficient in the management of in-process variations (Rotilio et al., 2019a) or in the planning of the work phases (Lucarelli et al., 2019). Lastly, from a practical point of view, there are still difficulties to plan clear and well-structured strategies. In this scenario, the topic of digitization in postscenario contexts requires some further reflections, which will be illustrated in the following chapter.

\section{DIGITISATION IN POST-DISASTER RECONSTRUCTION}

The assumption for a correct digitization of the existing built heritage consists in the intelligent collection and storage of available documentation. The focal point is precisely the availability of data, that today are still difficult to find or are missing. After all, although the building book file that contains all its information is mandatory by law, it is required a lot of time to investigate and find information. This operation is even more true when it is necessary to deal with contexts in postdisaster conditions, where it is often not possible to access paper data. For this reason, the digitization in these contexts is an even more advantageous methodological approach, because it allows to:

1. Create building "Identity Card";

2. Eliminate the paper information redundancy (if any), with the possibility to input data only once in the model in order to guarantee uniqueness and reliability;
The traditional construction workflow

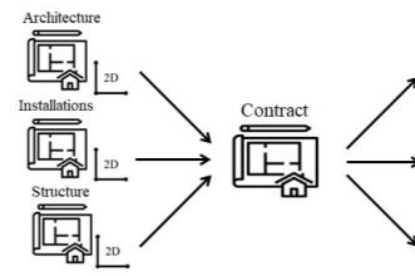

The construction workflow with BIM
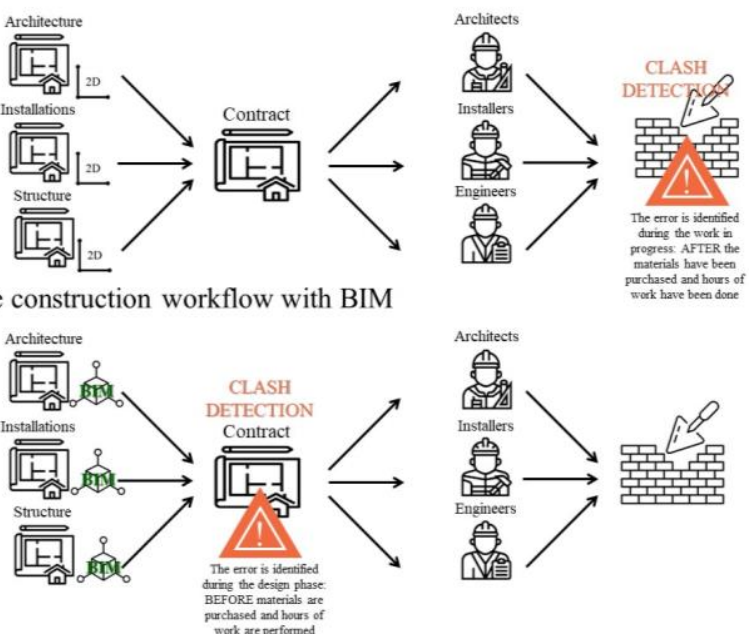

Figure 3. Comparison between the traditional construction workflow and the BIM one

3. Have a "dynamic" documentation, constantly updated;

4. Compensate for the lack of information regarding the building envelope, the architectural components (doors, windows ...) and the systems;

5. Collect all data into one large database, designed as a single information resource (Osello and Ugliotti, 2017).

Firstly, this digitization could represent the tool for design and construction, but above all, it could be useful for the building maintenance (Laurini et al., 2019). Secondly, it could allow the data exchange, limiting the loss of information and the resulting costs. Finally, according to need, it could be possible to establish the type of data and the detail level to which the model is to be set (Osello et al., 2015). In fact, the purpose of the modelling activity is to give a representation of the current state of the buildings, but also to create an intelligent database containing information related to its entire life cycle, from the construction to the end of life (Ciribini, 2019b).

The approach to digitization is absolutely not an immediate operation; it requires serious study, in order to check the needs and the organization of the work.

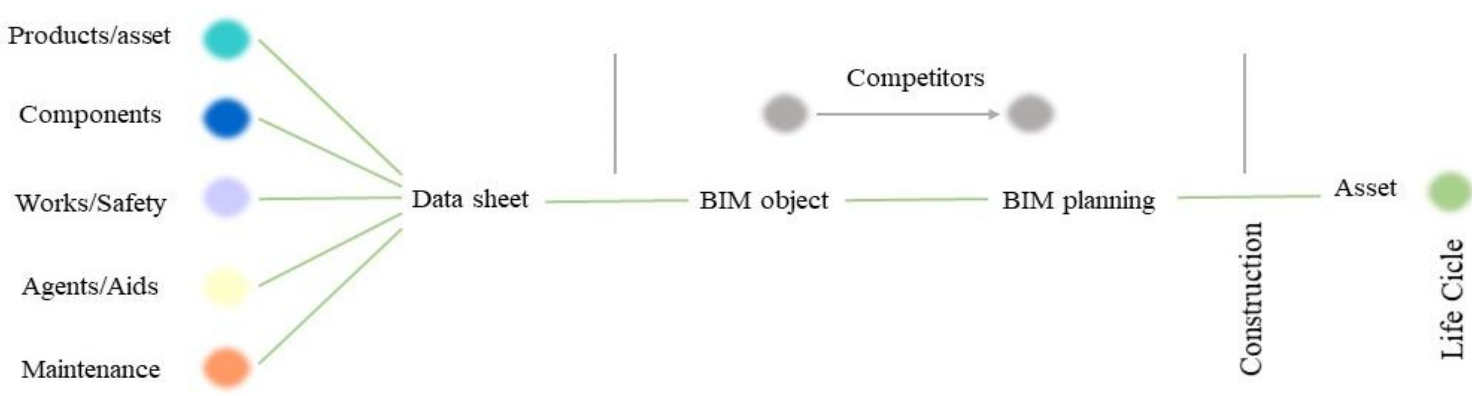

Figure 2. The INNOVance project is an example of an interoperable information exchange platform in the construction sector. It wants to promote the storage and structured extraction of information by the entire supply chain and in favour of the whole process, in order to allow this essential transition from graphic modeling to information management (Paravan et al., 2014). 
It is driven, on the one hand, by a series of regulatory obligations and, on the other, by the will of the designers to develop calibrated strategies for individual interventions, that want to be the driving force for a future methodological approach (Vilutiene et al., 2019).

In this complex scenario, it is clear that BIM reveals its usefulness also on site. Its use would facilitate the digitization of the execution phase of the work, so as to create a useful tool to guide, coordinate and support the intervention action through an integrated approach that allow to reach some benefits:

1. Ensuring safety;

2. Maximizing resources;

3. Ensuring coordination;

4. Predicting crisis situations;

5. Reducing the impact on the environment (Getuli et al., 2017).

Digitization in turn entails risks that could derive from the uncertainties of the still experimental method, which is far from the traditional approach, but it also gives rise to an enormous opportunity to eliminate the asymmetries that are the cause of today inefficiency (Ciribini et al., 2016). In fact, it is not a coincidence that many international experiences and experiments have been found regarding this methodology application in the context of post-disaster reconstruction. This latter is the centre of a countless amount of data which, if not properly controlled, could only generate chaos. The management of disasters in urban areas suffers from the lack of accurate and real-time information and from obstacles to sharing and collaboration. The data fragmentation is not helpful in post-disaster conditions, when efficiency and speed in knowledge are required. In this context, BIM is a "facilitator" of the interoperability of information for the built heritage and many areas of disaster management will benefit from its service in the near future.

Among the most important examples it is appropriate to mention the research by Messaoudi and Nawari (2020), which propose an innovative system to improve the reconstruction process, using Building Information Modelling. The study context is the Florida State, that often has been plagued by climate change and meteorological disasters. On the other hand, Kermanshachi and Rouhanizadeh (2018) have defined a methodology for automatic estimation of the construction costs of the different post-disaster reconstruction scenarios. This support tool for decision-makers is based on BIM. The latter is also at the heart of the research by Zeibak-Shini et al. (2016), that is aimed at using it in combination with the integrated Terrestrial Laser Scanning. This theory is intended to reconstruct the "as-damaged" model starting from the "as-built" one. Instead, Cheng et al. (2017) use BIM to identify an intelligent system of fire and rescue prevention in disasters case. In this instance, the study context is Taiwan. Nikoohemat et al. (2020) have developed a methodology to reconstruct expeditious three-dimensional models of large buildings with an automatic approach. These navigable models will be useful in the immediate post-disaster phase and they may be imported into BIM for subsequent investigations.

At last, a current technology object of great attention is the advanced virtual reality, that is used in the city of Sponge to simulate flood phenomena (Whang et al., 2019). The study combined hydrological, topographical and GIS data with realtime hydrodynamic models and with an interactive visualization in a three-dimensional environment.

With reference to the particular Italian context, after the proliferation of telluric events in the last decade, the digitization has gained prominent place, stimulating the interest of professionals. In fact, it was necessary to find a way to prevent or mitigate damage that occurs as a result of an extreme phenomenon (Gritti and Menoni, 2017).

Between the most interesting researches, it is possible to find the one by Brumana et al. (2017), that is based on the experience of the restoration of the Collemaggio Basilica in L'Aquila, severely damaged by the 2009 earthquake (Fig. 4). The work was entirely financed by ENIservizi which, aware of the potential of digitization, required an advanced HBIM from laser scanner and photogrammetric surveying. This approach would have supported the diagnostic phase, as well as the design phase. The Collemaggio Basilica restoration was really a significant intervention within the post-earthquake reconstruction process in L'Aquila, but also in the entire Italian context.

In this case, the authors have highlighted how the contract for the work, for an amount of approximately 14 million euros, anticipated the national legislation on public works, i.e. Legislative Decree 50.2016, aligned with the aforementioned Community Directive 2014/24/EU that introduced BIM. Going into the details of the intervention, the description of the survey, the diagnostic and the design processing phase with HBIM use was illustrated in detail by Oreni et al. (2017). The authors also highlighted the criticalities that actually still occur in the BIM use in the conservation sector, related to the creation of very complex models with irregular geometries and to this tool use by administrators and builders.

As part of the HBIM, it is also worth to report the experience made on San Cipriano Church in Castelvecchio Calvisio (Aq): the authors elaborate a research path aimed at understanding what are the application possibilities of this methodology to historical and archaeological architecture (Continenza et al. 2016).

Finally, a latest research is the one that is included within studies in place in recent years ${ }^{1}$ that led to the definition of the the Municipality of Fossa (Aq) construction plan, Fig. 5.

These studies had led to the development of a previous plan, that was useful for the rational, coordinated and safe management of the entire executive and construction process of the post-earthquake 2009 reconstruction of the minor centres in its entirety.

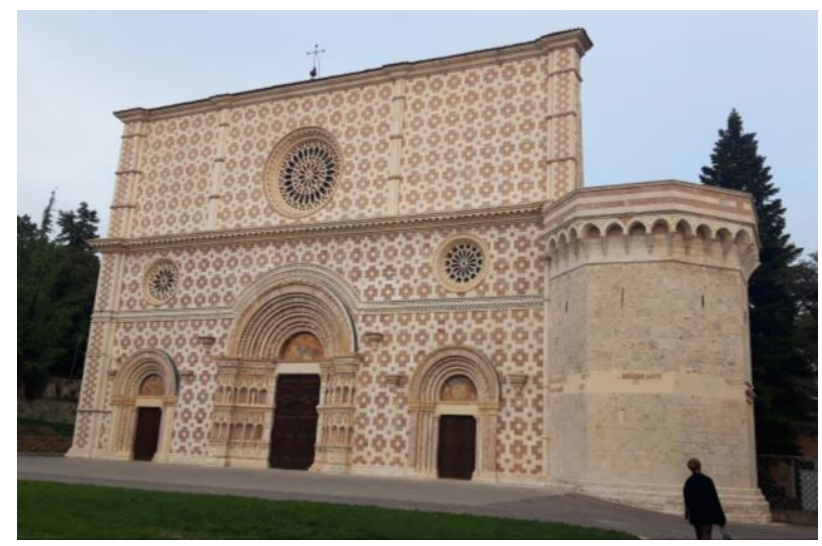

Figure 4. The Collemaggio Basilica in L'Aquila, that was restored after the 2009 earthquake

\footnotetext{
${ }^{1}$ The reference is to the research group "Production of the building industry and rational management of the construction process on site", DICEAA, University of Study of L'Aquila, Italy. Head of research: Prof. Pierluigi De Berardinis.
} 


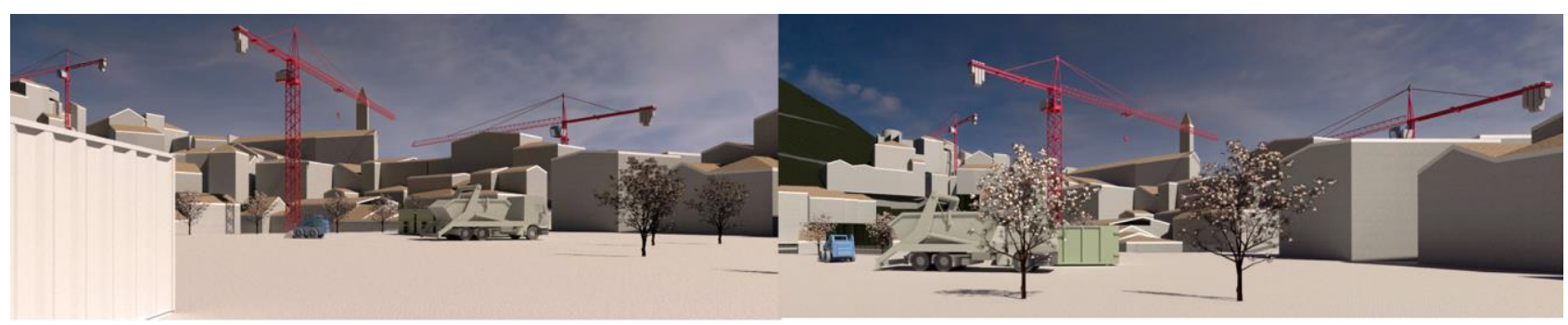

Figure 5. The digitization as a tool to control and support the construction site of minor historical centres, that were severely affected by the 2009 telluric events

The reference is to the Fontecchio construction site plan (Rotilio et al., 2019b), located in the Province of L'Aquila and severely damaged by the earthquake event.

Compared to the experience of Fontecchio, the digitalization strategies were implemented in Fossa ${ }^{2}$, in order to be able to rethink the executive project of every restoration in relation to the ones to be carried out in the other village buildings. Through the BIM methodology, it is possible to reach the following results:

1. The constant monitoring of the entire construction site;

2. The guarantee of constant updating and monitoring, because these interventions are dynamic over time;

3. The certainty of interaction between the parties;

4. The management of endogenous and exogenous conflicts of the single construction site.

\section{CONCLUSIONS}

The digitization is a phenomenon that is involving all the main production facilities, thanks to specific industrial policies conducted by each country. Likewise, the construction sector, that normally is not very open to process innovations, is involved with the same intensity, due to the potential that this innovation could entail in this specific context. Currently, many researchers devote time and resources to this specific research line, from different points of view. Overall, what has resulted is that the transformation process is still in progress; therefore, it brings advantages and disadvantages. Among them, the ones in evidence are: the greater efficiency in the whole design process and the work execution, the creation of a long-lasting data informative heritage, the costs optimization. On the contrary, the major critical issues are related to the lack of qualified professionals and perfect interoperability between the different software that are available on the market.

Thus, the analysis focused on the issue of digitization in postdisaster reconstruction. It is useful in order to create a suitable tool to guide, coordinate and support intervention, through an integrated approach. Sum up, the contribution is aimed at providing a progress overview of the digitization process in the present context, starting from its evolution in the construction world, up to the management of post-disaster scenarios.

\footnotetext{
${ }^{2}$ The study and the elaboration of the "Fossa Construction Site Plan" are the result of the agreement between the Municipality of Fossa, the DICEAA Department of the University of L'Aquila and the Ese-Cpt training institution.
}

\section{ACKNOWLEDGMENTS}

M.R. conceived the article, defined its structure, its organization and supervised it. She was also the corresponding author. M.R. and B.T. wrote the article in an equal manner.

\section{REFERENCES}

Brumana, R., Della Torre, S., Oreni, D., Previtali, M., Cantini, L., Barazzetti, L., Franchi, A., and Banfi, F. 2017. Hbim challenge among the paradigm of complexity, tools and preservation: the basilica di collemaggio 8 years after the earthquake (L'Aquila), Int. Arch. Photogramm. Remote Sens. Spatial Inf. Sci., XLII-2/W5, 97-104, https://doi.org/10.5194/isprs-archives-XLII-2-W5-97-2017.

Cheng, M.Y., Chiu, K.C., Hsieh, Y.M., Yang, I.T., Chou, J.S., Wu, Y.W., 2017. BIM integrated smart monitoring technique for building fire prevention and disaster relief, Automation in Construction, 84 , https://doi.org/10.1016/j.autcon.2017.08.027.

14-30,

Ciribini, A. L. C., 2018. Come cambierà digitalmente il settore delle costruzioni? Una riflessione, Ingenio, https://www.ingenio-web.it/20991-come-cambiera-

digitalmente-il-settore-delle-costruzioni-una-riflessione (access on 31.08 .2020 ).

Ciribini, A. L. C., 2019a. I limiti del BIM e le potenzialità del dato, Ingenio, https://www.ingenio-web.it/22624-i-limiti-delbim-e-le-potenzialita-del-dato (access on 31.08.2020).

Ciribini, A. L. C., 2019b. Dal cantiere digitalizzato al cantiere digitale: internet of the decision making project processes e impresa di costruzioni, Ingenio, https://www.ingenioweb.it/25512-dal-cantiere-digitalizzato-al-cantiere-digitaleinternet-of-the-decision-making-processes-e-lmpresacostruzioni (access on 31.08.2020).

Ciribini, A. L. C., Mastrolembo Ventura, S., Paneroni, M., 2016. Implementation of an interoperable process to optimise design and construction phases of a residential building: A BIM Pilot Project. Automation in Construction 71, 62-73.

Continenza, R., Trizio, I., Giannangeli, A., Tata, A., 2016. HBIM for restoration projects: case-study on San Cipriano Church in Castelvecchio Calvisio, Province of L'Aquila, Italy, Disegnarecon, 9(16), 15.1-15.9.

Ferrara, A., Feligioni, E., 2016 BIM e project Management, Dario Flaccovio Editore pagg. 16-25. 
Getuli, V., Mastrolembo Ventura, S., Capone, P., Ciribini, A. L. P., 2019. BIM-based code checking for construction health and safety. Procedia Engineering 196, 454 - 461.

Gritti, A., Menoni, S., 2017. La ricostruzione come metodo. Cosa insegna la storia recente degli eventi sismici in Italia. Urbanistica Informazioni, Special Issue 272(1), 766-768.

Kermanshachi, S., Rouhanizadeh, B., 2018. Feasibility Analysis of Post Disaster Reconstruction Alternatives Using Automated BIM-Based Construction Cost Estimation Tool, CSCE 6th International Disaster Mitigation Specialty, 13-16 June, Fredericton, Canada.

Laurini, E., Rotilio, M., Lucarelli, M., and De Berardinis, P. 2019. Technology 4.0 for buildings management: from building site to the interactive building book, Int. Arch. Photogramm. Remote Sens. Spatial Inf. Sci., XLII-2/W11, 707-714, https://doi.org/10.5194/isprs-archives-XLII-2-W11-707-2019.

Li, Y., Liao, Z., \& Yuan, H. (2014). Investigating the Impacts of BIM on project parties and its application, Construction Technology, 43(6), 522-523.

Lucarelli, M., Laurini, E., Rotilio, M., De Berardinis, P., 2018 Metodo BIM: gestione dei cantieri edilizi nei centri colpiti da calamità naturali. In: VI Edizione Convegno ReUso, Messina 11-12-13 Ottobre 2018 in ReUSO 2018, L'intreccio dei saperi per rispettare il passato interpretare il presente salvaguardare il futuro, a cura di Fabio Minutoli, Gangemi Editore: Roma, ISBN13: 9788849236590 ISBN10: 9788849236590.

Lucarelli, M., Laurini, E., Rotilio, M., and De Berardinis, P. 2019. Bep \& Mapping process for the restoration building site, Int. Arch. Photogramm. Remote Sens. Spatial Inf. Sci., XLII2/W11, 747-752, https://doi.org/10.5194/isprs-archives-XLII-2W11-747-2019.

Miramonti, C., 2014. BIM: il nuovo approccio per progettare e costruire, Dossier da Unificare \& Costruire 9), 27-42 http://www.pr.camcom.it/promozione/innovazionetecnologica/materiale-innovazione-tecnologica-2014/dossier-uc-n-9-2014-bim. (access on 26.08.2020).

Messaoudi, M., Nawari, N.O., 2020, BIM-based Virtual Permitting Framework (VPF) for post-disaster recovery and rebuilding in the state of Florida, International Journal of Disaster Risk Reduction, 42, https://doi.org/10.1016/j.ijdrr.2019.101349.

Nikoohemat, S., Diakité, A.A., Zlatanova, S., Vosselman, G., 2020. Indoor 3D reconstruction from point clouds for optimal routing in complex buildings to support disaster management, Automation in Construction, 113, 103109, https://doi.org/10.1016/j.autcon.2020.103109.

Nosegno, N., 2005 Enciclopedia dei ragazzi. Treccani, Roma. http://www.treccani.it/enciclopedia/digitalizzazione_(Enciclope dia-dei-ragazzi)/ (access on 26.08.2020).

Oreni, D., Brumana, R., Della Torre, S., and Banfi, F. 2017. Survey, Hbim and conservation plan of a monumental building damaged by earthquake, Int. Arch. Photogramm. Remote Sens. Spatial Inf. Sci., XLII-5/W1, 337-342, https://doi.org/10.5194/isprs-archives-XLII-5-W1-337-2017.
Osello, A., (Ed.) 2015. BIM Building Information Modelling Geographic Information System, Augmented Reality per il Facility Management, Dario Flaccovio Editore, Palermo.

Osello, A., Ugliotti, F. M., 2017. BIM Building Information Modelling verso il catasto del futuro. Conoscere, digitalizzare, condividere. Il caso studio della città di Torino, Gangemi editore, Roma.

Pavan, A. et. al. 2014. Construction Information Management (CIM), INNOVance for the construction process, In: Energy, sustainability and building information modeling and management" A. Ciribini et al. (Eds.), Segrate, Maggioli, 15-33.

Qin, X., Shi, Y., Lyu, K., Mo, Y., 2020. Using a Tam-Toe model to explore factors of building information modelling (BIM) adoption in the construction industry, Journal of Civil Engineering and Management 26(3) 259-277.

OICE 2019 "Rapporto sulle gare BIM 2019 per opere pubbliche, Analisi del mercato e delle gare", Roma.

Rotilio, M., Laurini, E., Lucarelli, M., and De Berardinis, P. 2019a. The maximization of the 4th dimension of the building site, Int. Arch. Photogramm. Remote Sens. Spatial Inf. Sci., XLII-4/W17, 15-20, https://doi.org/10.5194/isprs-archivesXLII-4-W17-15-2019.

Rotilio, M., Laurini, E., De Berardinis, P., Fradiani, L., 2019b. Construction site plan. The case study of Fontecchio (AQ), In: REHAB 2019 - Proceedings of the 4rd International Conference on Preservation, Maintenance and Rehabilitation of Historical Buildings and Structures, Barcelos: Greenlines Institute for Sustainable Development, Guimares, Portugal, 1719 July, 553-564, ISBN 978-989-8734-41-9.

UNI 11337:2009 Edilizia e opere di ingegneria civile - Criteri di codificazione di opere e prodotti da costruzione, attività e risorse - Identificazione, descrizione e interoperabilità.

UNI 11337-1:2017 Edilizia e opere di ingegneria civile Gestione digitale dei processi informativi delle costruzioni Parte 1: Modelli, elaborati e oggetti informativi per prodotti e processi.

Van Nederveen, G. A., Tolman, F. P., 1992. Modelling multiple views on buildings. Automation in Construction 1(3), 215-224.

Vilutiene, T., Hosseini, M.R., Pellicer, E., Zavadskas, E.K., 2019. Advanced BIM Applications in the Construction Industry, Advances in Civil Engineering, 2019, ID 6356107, https://doi.org/10.1155/2019/6356107.

Wang, C., Hou, J., Miller, D., Brown, I., Jiang, Y., 2019. Flood risk management in sponge cities: The role of integrated simulation and 3D visualization, International Journal of Disaster Risk Reduction,39,101139, https://doi.org/10.1016/j.ijdrr.2019.101139.

Zeibak-Shini, R., Sacks, R., Ma, L., Filin, S., 2016. Towards generation of as-damaged BIM models using laser-scanning and as-built BIM: First estimate of as-damaged locations of reinforced concrete frame members in masonry infill structures, Advanced Engineering Informatics, 30(3), 312-326, https://doi.org/10.1016/j.aei.2016.04.001. 